American Journal of Pharmaceutical Education 2008; 72 (3) Article 56.

\title{
VIEWPOINTS
}

\section{Leadership and Learning}

\author{
Gayle A. Brazeau, PhD \\ Associate Editor, American Journal of Pharmaceutical Education
}

In a speech prepared for John F. Kennedy to be given on that fateful day in Dallas in 1963, we were to be reminded that "Leadership and learning are indispensable to each other." Indispensable elements are those elements that are absolutely necessary, obligatory, essential, or requisite; incapable of being disregarded; necessary; that cannot be done without; neglected; or unavoidable to each other. ${ }^{1}$ This intrinsic relationship between leadership and learning is particularly relevant in higher education today as articulated in the vision, mission, and goals of universities and colleges to focus on student learning while at the same time developing the skills and abilities in future generations of leaders. Pharmacy educators have also found leadership and learning to be indispensible to each other given the elements of current accreditation standards and guidelines.

The American Council for Pharmacy Education Standards 2007 cites elements of leadership and learning for our professional programs and organizations. ${ }^{2}$ Leadership is mentioned in relationship to our mission and goals, college or school organization and governance, and the responsibilities of the dean (Standards 1 7,8); student admissions criteria (Standard 17); student representation and perspectives and professional behavior and harmonious relations (Standards 22 and 23); faculty and staff continuing professional development and performance review (Standard 26); the Joint Commission of Pharmacy Practitioners Future Vision of Pharmacy Practice in 2015 (Appendix A); and the guidance on the science foundation for our curriculum (Appendix B). Learning is also a fundamental element of Standards 2007 with references to learning (not including distance learning) in mission and goals and evaluation of achievement of mission and goals (Standards 1 and 3); qualifications of the dean (Standard 8); the goal of the curriculum, curricular development, delivery and improvement, teaching and learning methods, curricular core and the pharmacy practice experiences, and assessment and evaluation of

Corresponding Author: Gayle A. Brazeau, PhD. Associate Editor, American Journal of Pharmaceutical Education, University at Buffalo, School of Pharmacy and Pharmaceutical Sciences. E-mail: gbrazeau@buffalo.edu. student learning and curricular effectiveness (Standards 9-11 and 14-15); progression of students and professional behavior and harmonious relations (Standards 19 and 23); faculty and staff qualitative factors (Standard 25); and physical and practice facilities and library and educational resources (Standards 27-29) and pharmacy practice experiences (Appendix C). These standards and guidelines include leadership and learning for all elements associated with our professional programs from the structure and organization of our colleges and schools; administration; faculty and staff members; students; curriculum and experiential education; and physical and practice educational resources.

In our former president's statement, leadership is mentioned before learning. No one can know for sure why the word leadership was placed prior to learning when crafting this sentence, but one can speculate possible reasons for the organization of this sentence. The word leadership certainly comes before learning in the alphabet, or perhaps it sounded better than the other way around given the context and organization of the remainder of the text for this speech. However, I would contend that the order is appropriate, it is leadership that helps to formulate the emphasis on learning, and learning helps to improve our leadership. Successful organizations empower individuals and teams across all levels to effectively articulate and work towards their vision, mission, and goals, and promote a culture of learning as the foundation for quality improvement and growth. Each individual contributes and is accountable for his/her actions as an individual and leader to their organization.

Faculty, students, practitioners, preceptors and staff members in pharmacy education are accountable to our patients, to our colleagues, and to ourselves as we discover and advance knowledge, promote lifelong learning, promote successful patient outcomes, and enhance professional practice. The desired successful outcome(s) and overall care for our patients must be our focus in the discovery and development of new therapeutic modalities, drug delivery systems, therapeutic guidelines, and methods for optimizing patient medication usage. Intellectual curiosity and a willingness to learn are central to students, faculty members, practitioners, and preceptors 


\section{American Journal of Pharmaceutical Education 2008; 72 (3) Article 56.}

as they strive to better improve the care of their patients. Each of us must also assume a leadership and educators' role in ensuring our patients' understanding and involvement in their care.

Each of us also takes a leadership role in our accountability to each other as we learn and improve our organizations. We must be willing to assume leadership roles, as needed, to ensure the successes of other individuals and teams in our colleges and schools. We must be willing to learn the new skills needed to effectively work and collaborate in a team environment and to better utilize our individual leadership skills. Learning is essential to the success of teams and groups in our own organizations. Learning and utilizing knowledge and skills needed to improve team dynamics, learning, and outcomes must be the focus for professional education and development. We also must provide opportunities for faculty members, students, practitioners, preceptors, and staff members to enhance their skills as leaders through educational programs. Leadership skills and tools can be learned from individuals across our colleges and schools.

Individuals are also accountable to themselves. We must be willing to continually enhance knowledge and skills in our professional development through available learning opportunities in our organizational and professional societies or through reading the literature, references, or other books. Learning can only be achieved by an individual. Continuous professional development and improvement is the hallmark of an individual who can contribute to the success of their organization through assuming leadership roles and mentoring others in leadership roles. Leaders, in turn, must facilitate the settings and opportunities for their colleagues to enhance their leadership abilities.

Leadership and learning should never be considered separate, distinct elements in our educational programs. Each of us must always be willing to learn and to lead as we strive towards academic, professional and personal excellence in our colleges and schools.

\section{REFERENCES}

1. Dictionary.com. Available at: http://dictionary.reference.com/ browse/indispensable Accessed May 18, 2008.

2. Accreditation Council for Pharmacy Education, Accreditation Standards and Guidelines for the Professional Program in Pharmacy Leading to the Doctor of Pharmacy Degree. Effective July 1, 2007, Available at: http://www.acpe-accredit.org/deans/standards.asp Accessed May 18, 2008. 